\title{
Effects of noise and vibration on learning task and subjective ratings of disturbance
}

\author{
Takumasa Yoshida* and Nobusuke Sakata** \\ *Department of Architectural Hygiene Engineering and Housing, \\ The Institute of Public Health, \\ 4-6-1, Shiroganedai, Minato-ku, Tokyo, 108 Japan \\ **Department of Architecture, Faculty of Engineering, Kyushu University, \\ 6-10-1, Hakozaki, Higashi-ku, Fukuoka, 812 Japan
}

(Received 6 January 1986)

\begin{abstract}
Experiments on individual and combined effects of noise and vibration of low or moderate intensity were conducted concerning paired associates learning task. The experiments concerned randomly intermittent noise at 64,74 and $79 \mathrm{~dB}(\mathrm{~A})$ (re $20 \mu \mathrm{Pa}$, peaks az) and continuous or intermittent vibration at 66 and $76 \mathrm{~dB}\left(\mathrm{re} 10^{-5} \mathrm{~m} / \mathrm{s}^{2}\right.$, vertical wholebody sinusoidal in $5 \mathrm{~Hz}$ ). The learning task was evaluated by error rates in mean and standard deviation for each condition of noise and vibration. Subjective ratings of disturbance by noise and vibration were also made after the task. Sixty-four and $79 \mathrm{~dB}(\mathrm{~A})$ noise produced detrimental effects on the learning. Seventy-nine dB(A) noise added with the continuous vibration indicated elimination of the effects of noise and vibration alone. Further, high disturbance did not always accompany high error rates in mean or standard deviation.
\end{abstract}

PACS number: 43. 50. Qp, 43. 66. Wv

\section{INTRODUCTION}

Noise and vibration in low or moderate intensity, not yet high, may cause some problems in nonoccupational environments (schools, offices or home environments etc.). ${ }^{1,2)}$ Earlier researches with questionnaires indicated some mental effects of noise following after annoyance, speech interference and sleep disturbance. ${ }^{3)}$ By the way, such mental effects may be considered to cause some effects on performance as well as physical effects of vibration. The results to date showed that noise (or vibration) produced sometimes deterioration and sometimes promotion in performance of the tasks. ${ }^{4-7)}$ Especially, individual or combined effects of noise and vibration are not clear in low or moderate intensity. Therefore, more systematical researches are required in this area ${ }^{8}$

This study concerned paired associates learning task, intermittent noise and vibration (continuous or intermittent). The experiments were also conducted with three aspects; first, individual effects of noise or vibration; second, combined effects of noise and vibration; third, subjective ratings of disturbance by noise and vibration in relation to mean or standard deviation of error rates.

\section{EXPERIMENTAL PROCEDURE}

\subsection{Noise and Vibration}

Twenty-four conditions of noise and vibration were employed in this study, that contained individual and combined conditions of those.

Noise employed was broad-band intermittent noise. The noise was produced by passing through a random switch which could cut or pass signals in random intervals and durations. ${ }^{9)}$ The noise was presented at levels of 64,74 and $79 \mathrm{~dB}(\mathrm{~A})$, peaks az (re $20 \mu \mathrm{Pa}$ ). These are designated as $\mathrm{N}_{1}, \mathrm{~N}_{2}$ or $\mathrm{N}_{8}$ respectively. Instruments to present the noise were a amplifier (SONY 1120), a loudspeaker (Mitsubishi AS 2051B) and a pink noise generator (Brüel \& Kjær 1402). The loudspeaker was set in a distance 
of $1.2 \mathrm{~m}$ from the center of a desk secured to the platform of a shaker. ${ }^{10)}$

Vibration employed was whole-body sinusoidal and vertical in $5 \mathrm{~Hz}$. The vibration was presented continuously or intermittently at levels of 66 and 76 $\mathrm{dB}\left(\mathrm{re} 10^{-5} \mathrm{~m} / \mathrm{s}^{2}\right)$ measured at the center of a chair secured to the platform of the shaker. Intermittent vibration was presented at intervals of $6 \mathrm{~s}$ with durations of $14 \mathrm{~s}$ that involved rise- and decay-time of $2 \mathrm{~s}$ respectively. Continuous vibration is designated here as $\mathrm{CV}_{1}(66 \mathrm{~dB})$ or $\mathrm{CV}_{2}(76 \mathrm{~dB})$ and intermittent vibration is designated as $\mathrm{IV}_{1}(66 \mathrm{~dB}$, peaks az) and $\mathrm{IV}_{2}(76 \mathrm{~dB}$, peaks az). Combined conditions were composed of one of $\mathrm{N}_{1}, \mathrm{~N}_{2}$ or $\mathrm{N}_{3}$ added with one of $\mathrm{CV}_{1}, \mathrm{CV}_{2}, \mathrm{IV}_{1}$ or $\mathrm{IV}_{2}$. These twelve conditions are designated as $\mathrm{N}_{1}+\mathrm{CV}_{1}, \mathrm{~N}_{2}+$ $\mathrm{CV}_{1}, \mathrm{~N}_{8}+\mathrm{CV}_{1}, \mathrm{~N}_{1}+\mathrm{CV}_{2}, \mathrm{~N}_{2}+\mathrm{CV}_{2}, \mathrm{~N}_{3}+\mathrm{CV}_{2}, \mathrm{~N}_{1}+$ $I V_{1}, N_{2}+I V_{1}, N_{3}+I V_{1}, N_{1}+I V_{2}, N_{2}+I V_{2}$ and $N_{3}+$ $\mathrm{IV}_{2}$. By the way, the conditions of the vibration accompanied with noises of a cooling fan for the driver of the shaker and a oil pump that ranged from $58 \sim$ $60 \mathrm{~dB}(\mathrm{~A}), L_{\mathrm{eq}}(10: 00 \sim 16: 00)$. The conditions of these noises are designated as $B$ that continued during the electric main of the shaker being on. So conditions of $B, N_{1}+B, N_{2}+B$ and $N_{3}+B$ were also in use as experimental conditions. Control was a condition of no-vibration and a background noise in the experimental room during the main of the shaker

Table 1 Conditions of noise and vibration.

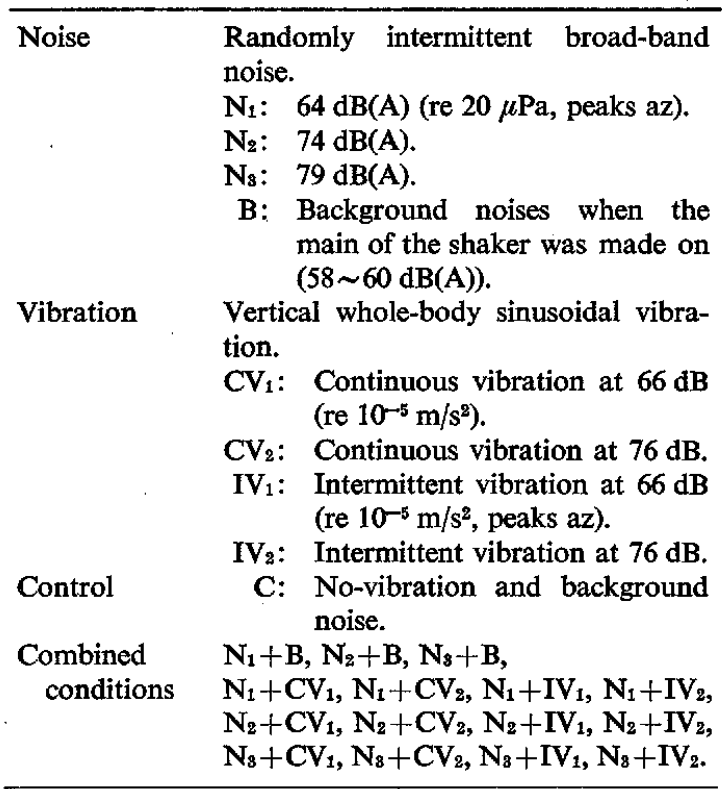

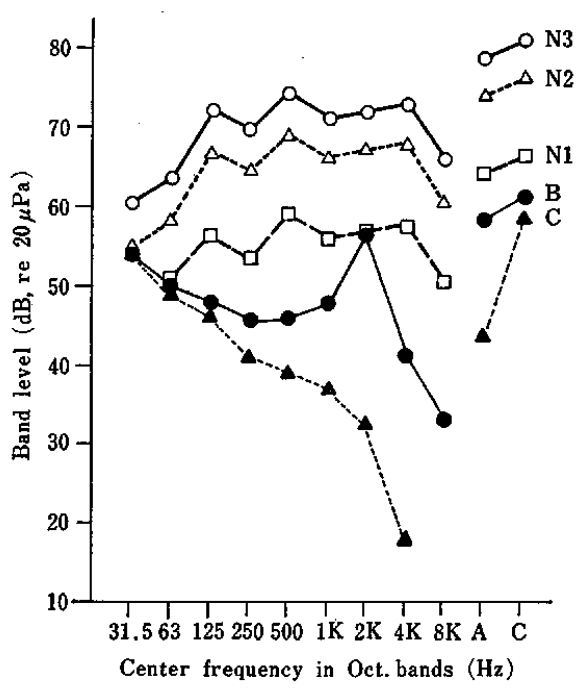

Fig. 1 Frequency characteristics of noise $\left(N_{1}, N_{2}, N_{8}, B\right)$ and the background noise in the control (C).

being off. This is designated as C. All conditions of the noise and the vibration are indicated in Table 1 and characteristics of frequency of the noise are shown in Fig. 1.

\subsection{Subjects}

Six male and two female students with ages ranging from 18 to 22 years were used as subjects. They were in normal health and had normal hearing functions and normal vision. They had no previous experience with the task and the apparatus used in this study. No information about effects of noise and vibration was not given to the subjects. They were volunteers paid for their tasks. Each subjects sat on the chair with the desk which were fixed on the platform of the shaker. They experienced the vibration mainly through their buttocks via the chair.

\subsection{Task}

Paired associates learning (PAL) and choice reaction time task were employed as experimental task. Results about reaction time task will be reported in another paper. So results about paired associates learning are mentioned here. The task of paired associates learning was conducted in the following manner.

Each subject was required to recall each half list during $40 \mathrm{~s}$ with cue of presenting the other half of 


\section{T. YOSHIDA and N. SAKATA: EFFECTS OF NOISE AND VIBRATION ON TASK}

each list, after memorizing each list of ten pairs of words during a period of $40 \mathrm{~s}$. This task was repeated successively with five trials in each session of each subject. Words in the lists consisted of two Japanese syllables that had non-association values from 0 to 4. Characters in each list was presented by a projecter (Kodak EXTRAGRAPHIC B-2) in a size of $5 \mathrm{~cm} \times 5 \mathrm{~cm}$ on a screen which was set in a distance of $3.5 \mathrm{~m}$ from the center of the desk.

\subsection{Procedure}

Task experiments were conducted in two days for each pair of the subjects. The subjects were assigned to four pairs before the experiments. Each pair was examined in turn for eight experimental sessions in a day. While one subject was examined on his or her task, the other one had been waiting in a next quiet room. Three sessions were held in the morning and five sessions in the afternoon. Each session was composed with 5 min of choice reaction time task and 15 min of paired associates learning task. Experimental design was planned by a block design.

\section{ANALYSIS OF DATA}

The paired associates learning task was evaluated with two measures of mean and standard deviation as regards error rates in each condition of each subject. The error rates mentioned above contained rates not recalled. All data in each measure were analyzed by Hayashi's Quantification Method (Type 1). Estimated values of this method are defined in the following equation. ${ }^{11)}$

$$
\begin{gathered}
\alpha=\sum_{j=1}^{R} \sum_{k=1}^{K} \delta(j k) x_{j k}, \\
\delta(j k)=\left\{\begin{array}{cc}
1 \text { (if a data follows } k \text { category } \\
\text { in } j \text { item), } \\
0 \text { (if a data does follow a category } \\
\text { besides } k \text { ) }
\end{array}\right. \\
\alpha: \quad \text { outside variable } \\
x_{j k}: \quad \text { estimated value of } k \text { category in } j \text { item. }
\end{gathered}
$$

In preliminary analyses for each measure of error rates, variable of "day" was not useful and then four variables were used for analytical items in this method. The variables were "noise and vibration" (NV), "subjects" (Sub), "materials for memory" (Mt) and "sessions" (Ses).

Subjects were required to rate disturbance by noise and vibration after each task in the experimental sessions. Disturbance was evaluated in a scale of
Table 2 Values in Likert's scale $(L)$ versus the values in the subjective rating scale of disturbance $(D)$.

\begin{tabular}{llllll}
\hline Scale & \multicolumn{5}{c}{ Scale values } \\
\hline$D$ & 1 & 2 & 3 & 4 & 5 \\
$L$ & 1.0 & 2.08 & 3.02 & 3.92 & 5.0 \\
\hline
\end{tabular}

five orders from 1 (disturbed not at all) to 5 (very disturbed). There was no comments at each number of the scale except 1 and 5, and it was assumed that this scale was linear with same intervals. Then, data of the subjective ratings of disturbance were also analyzed by Hayashi's Quantification Method (Type 1) with the same variables to those in the analyses of performance.

By the way, the assumption for this rating scale of disturbance was tested in preliminary analysis by Hayashi's Quantification Method (Type 2) ${ }^{12}$ ) with the same items (variables) to those in the analysis by Hayashi's Quantification Method (Type 1) (used in this study). The five rank numbers in the rating scale of disturbance were used for outside categories in this preliminary analysis. Results of the preliminary analysis showed that quantified values for each conditions of noise and vibration highly correlated $(r=0.939)$ to quantified values for the NV's conditions (mentioned below in this study) analyzed by the quantification method of Type 1. This suggested that the assumption for the rating scale of disturbance would be almost true. Further, this assumption was also tested in preliminary analysis by using Likert's scale. ${ }^{13)}$ Results were represented to be equal values in the both polar values of the scales. Table 2 indicates Likert's scale in relation to the subjective rating scale of disturbance. This table also suggested that the assumption for the rating scale of disturbance would be almost true. So these preliminary analyses indicated that values rated by subjects in the subjective rating scale of disturbance could be analyzed as numerical data for outside variable of Hayashi's Quantification Method (Type 1). Results of the subjective ratings of disturbance analyzed by the quantification method of Type 1, using the data not changed to Likert's scale, are showed in the following.

\section{RESULTS}

4.1 Variables to Explain the Task Performance Tables 3 and 4 show intercorrelations among the 
Table 3 Intercorrelations among the variables, partial correlations of each variable and multiple correlation analyzed by Hayashi's Quantification Method (Type 1) as regards mean of error rates of PAL.

\begin{tabular}{lcccc}
\hline \multicolumn{1}{c}{ Variables } & Noise and vibration & Subjects & Sessions & Materials \\
\hline Subjects & -0.033 & & & \\
Sessions & 0.025 & 0.043 & & \\
Materials & -0.060 & 0.061 & -0.131 & \\
\hline (Partial correlation) & $0.616^{* * *}$ & $0.900^{* * *}$ & $0.289^{* *}$ & $0.657^{* * *}$ \\
(Multiple correlation) & $0.924^{* * *}$ & & & \\
\hline
\end{tabular}

*** and ** show statistical significance at levels of $p<0.001$ and $p<0.01$ respectively.

Table 4 Intercorrelations among the variables, partial correlations of each variable and multiple correlation analyzed by Hayashi's Quantification Method (Type 1) as regards standard deviation of error rates of PAL.

\begin{tabular}{lcccc}
\hline \multicolumn{1}{c}{ Variables } & Noise and vibration & Subjects & Sessions & Materials \\
\hline Subjects & 0.018 & & & \\
Sessions & $-0.218^{*}$ & -0.012 & \\
Materials & -0.188 & 0.041 & $-0.310^{* *}$ & \\
\hline (Partial correlation) & $0.674^{* * *}$ & $0.483^{* * *}$ & $0.487^{* * *}$ & $0.606^{* * *}$ \\
(Multiple correlation) & $0.774^{* * *}$ & & & \\
\hline$* * *, * *$ and ${ }^{*}$ show statistical significance at levels of $p<0.001, p<0.01$ and $p<0.05$ respectively.
\end{tabular}

variables, partial correlations of each variable and multiple correlations in the analyses for each measure of error rates with Hayashi's Quantification Method (Type 1). Both of Tables 3 and 4 showed high multiple correlations $(p<0.001)$ in each analysis for the measures of mean and standard deviation of error rates. The variables (NV, Sub and $\mathrm{Mt}$ ) indicated high partial correlations $(p<0.001)$ in these tables. While Ses indicated a high partial correlation in the analysis for the standard deviation, Ses indicated rather low partial correlation in the analysis for the mean. NV showed a highest partial correlation in the analysis for the standard deviation (sd), but NV showed a equivalent partial correlation to Mt. Sub showed a highest partial correlation in the analysis for the mean.

As regards intercorrelations among the variables, Tables 3 and 4 showed low correlations among each variable except those between NV and Ses and between Ses and Mt in the analysis for the sd. This could be considered to be due to the block design employed in this study. Tables 3 and 4 indicated in the results that the task performance could be explained by the four variables of NV, Sub, Mt and Ses.

4.2 Effects of Noise and Vibration on the Task Performance

Figures $2 \sim 6$ show quantified values for each condition of noise and vibration, when each measure of mean or sd was respectively used as outside variable in the quantification method (Type 1).

Parentheses (a) and (b) in these figures concern mean and sd of error rates respectively.

Figure 2 concerns the effects of the noise alone $\left(N_{1}, N_{2}, N_{3}\right)$ and the conditions with $B\left(B, N_{1}+B\right.$, $N_{2}+B, N_{3}+B$ ) as compared with the effects of $C$. $N_{1}$ and $N_{3}$ showed a higher mean of error rates than $\mathrm{C}(p<0.05) . \quad \mathrm{N}_{2}$ showed a slightly higher mean of error rates. These indicates that the intermittent noise alone have deterioration in performance, especially $\mathrm{N}_{1}$ or $\mathrm{N}_{3}$, although no differences in sd of error rates were shown in Fig. 2 among $\mathrm{N}_{1}, \mathrm{~N}_{2}, \mathrm{~N}_{8}$ and $\mathbf{C}$.

B showed a slightly higher mean of error rates than $\mathrm{C}$ and showed no difference in sd of error rates from $\mathrm{C}$ (see Fig. 2). But $\mathrm{N}_{1}+\mathrm{B}$ showed a lower mean of error rates than $N_{1}(p<0.05) . \quad N_{2}+B$ and 


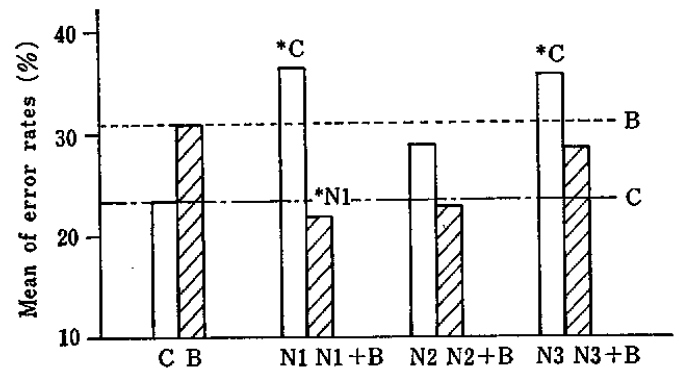

(a) Mean of error rates.

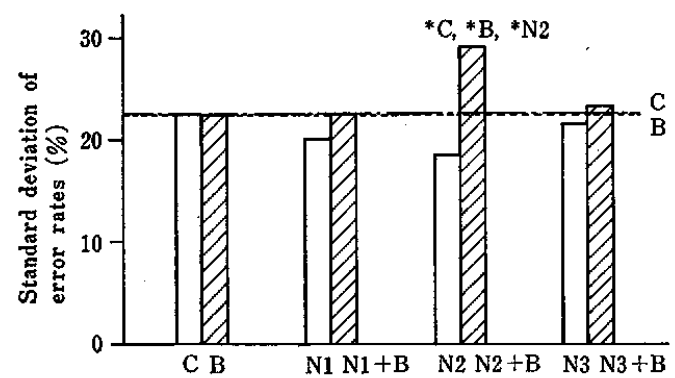

(b) Standard deviation of error rates.

Fig. 2 Estimated effects of noise under $\mathrm{N}_{1}$, $\mathbf{N}_{2}, \mathbf{N}_{8}, \mathbf{N}_{1}+\mathrm{B}, \mathrm{N}_{2}+\mathrm{B}, \mathrm{N}_{8}+\mathbf{B}, \mathrm{B}$ and the control (C). ${ }^{*} \mathrm{C}$ indicates statistical significance from $\mathrm{C}$ at $p<0.05$. ${ }^{*} \mathrm{~N}_{1}$ also indicates statistical significance from $\mathrm{N}_{1}$ at $p<0.05$.

$\mathrm{N}_{8}+\mathrm{B}$ also showed similar tendencies in mean of error rates to $N_{1}+B . N_{1}+B$ and $N_{8}+B$ showed no differences in sd of error rates from $\mathrm{N}_{1}$ and $\mathrm{N}_{3}$ respectively, while $\mathrm{N}_{2}+\mathrm{B}$ showed a larger sd of error rates than $\mathrm{N}_{2}(p<0.05)$ or $\mathrm{B}(p<0.05)$. By the way, $\mathrm{N}_{1}+\mathrm{B}, \mathrm{N}_{2}+\mathrm{B}$ and $\mathrm{N}_{8}+\mathrm{B}$ showed small differences in mean of error rates from $C$. Therefore, noise with $B$ indicated tendencies of eliminating the effects of noise alone.

Figure 3 is concerned with the vibration alone $\left(\mathrm{CV}_{1}, \mathrm{CV}_{2}, \mathrm{IV}_{1}, \mathrm{IV}_{2}\right) . \mathrm{CV}_{1}$ showed a higher mean of error rates $(p<0.05)$ than $C . \mathrm{CV}_{2}, \mathrm{IV}_{1}$ and $\mathrm{IV}_{2}$ also showed slightly higher mean of error rates. But $\mathrm{CV}_{1}$, $\mathrm{CV}_{2}, I V_{1}$ and $I V_{2}$ showed little differences in mean of error rates from $B$. The effects of the vibration alone was little, because the vibration accompanied with $B$ (see Sect. 2.1). $C V_{2}$ and $I V_{2}$ showed smaller sd's of error rates than $\mathbf{C}$ or $\mathbf{B}(p<0.05)$. So the effects of the vibration alone was appeared in sd of error rates, because $\mathrm{CV}_{2}$ and $\mathrm{IV}_{2}$ had higher levels of vibration than $\mathrm{CV}_{1}$ or $\mathrm{IV}_{1}$ respectively.

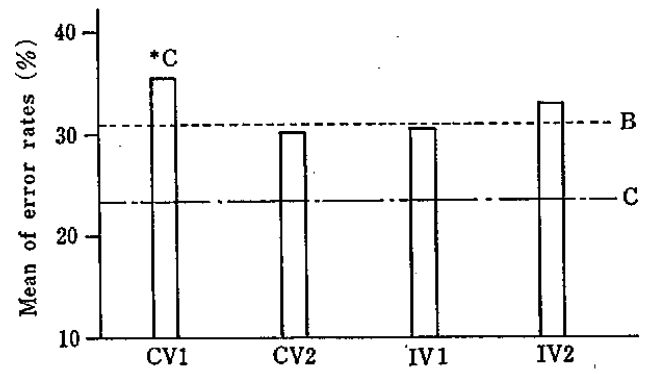

(a) Mean of error rates.

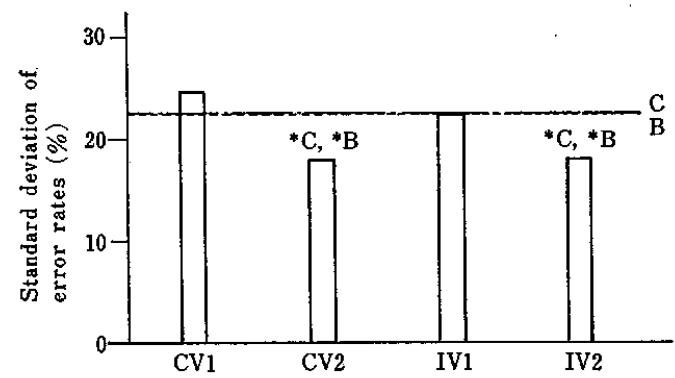

(b) Standard deviation of error rates.

Fig. 3 Estimated effects of vibration under $\mathrm{CV}_{1}, \mathrm{CV}_{2}, \mathrm{IV}_{1}$ and $\mathrm{IV}_{2} .{ }^{*} \mathrm{C}$ indicates statistical significance from $\mathrm{C}$ at $p<0.05$. ${ }^{*} B$ also indicates statistical significance from B at $p<0.05$.

Figure 4 concerns $\mathrm{N}_{1}$-noise added with each vibration. $\mathrm{N}_{1}+\mathrm{CV}_{1}$ showed a higher mean of error rates $(p<0.05)$, but showed a little difference in mean of error rates from $\mathrm{N}_{1}$ or $\mathrm{CV}_{1}, \mathrm{~N}_{1}+\mathrm{CV}_{2}, \mathrm{~N}_{1}+\mathrm{IV}_{1}$ and $N_{1}+I V_{2}$ showed little differences in mean from each vibration alone $\left(\mathrm{CV}_{2}, \mathrm{IV}_{1}, \mathrm{IV}_{2}\right)$ or $\mathrm{N}_{1}, \mathrm{~N}_{1}+\mathrm{CV}_{1}$ and $N_{1}+I V_{2}$ showed smaller sd's of error rates than $\mathrm{N}_{1}$ or each of $C V_{1}$ and $\mathrm{IV}_{2}$ respectively $(p<0.05)$. $\mathrm{N}_{1}+\mathrm{CV}_{1}, \mathrm{~N}_{1}+\mathrm{CV}_{2}$ and $\mathrm{N}_{1}+\mathrm{IV}_{2}$ also showed smaller sd's of error rates than $\mathrm{C}$. These results resembles to those of the vibration alone, especially in mean of error rates (see Figs. 3 and 4).

Figure 5 concerns $\mathrm{N}_{2}$-noise added with each vibration. $\mathrm{N}_{2}+\mathrm{CV}_{2}$ showed a slightly higher mean of error rates than $\mathrm{CV}_{2}$, that was statistically higher than $\mathrm{C}(p<0.05)$. The other combined conditions relating to $\mathrm{N}_{2}$ showed little differences in mean of error rates. As regards sd's of error rates, $\mathbf{N}_{2}+\mathrm{CV}_{1}$ showed a smaller sd than $\mathrm{CV}_{1}(p<0.05) . \quad \mathrm{N}_{2}+\mathrm{IV}_{1}$ showed a larger sd than $\mathrm{N}_{2}(p<0.05) . \quad \mathrm{N}_{2}+\mathrm{CV}_{2}$ and $\mathrm{N}_{2}+\mathrm{IV}_{2}$ showed smaller sd's than $\mathrm{C}(p<0.05)$. 


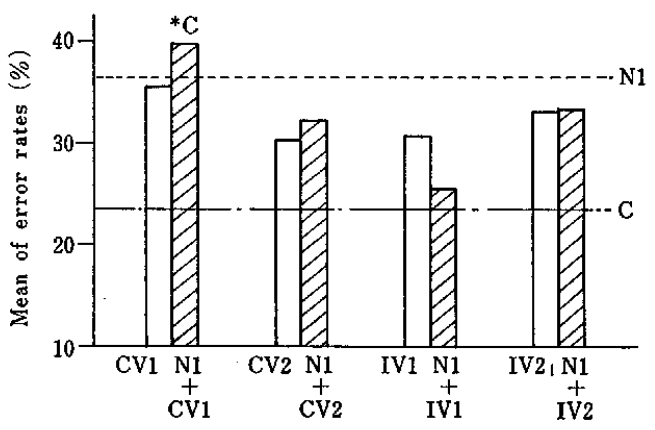

(a) Mean of error rates.

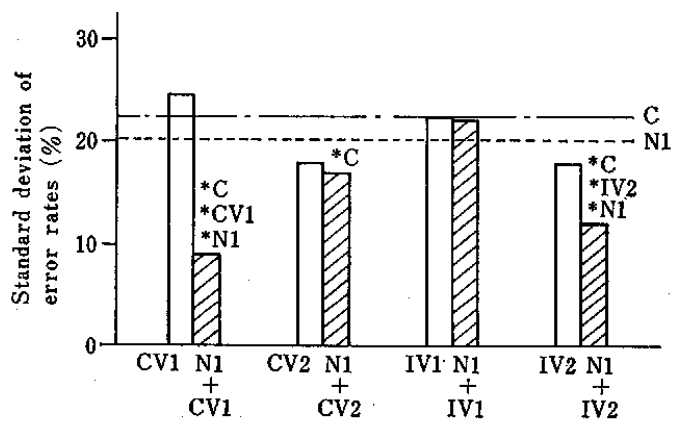

(b) Standard deviation of error rates.

Fig. 4 Estimated combined effects of noise and vibration under $\mathrm{N}_{1}+\mathrm{CV}_{1}, \mathrm{~N}_{1}+\mathrm{CV}_{2}$, $\mathrm{N}_{1}+\mathrm{IV}_{1}$ and $\mathrm{N}_{1}+\mathrm{IV}_{2}$. ${ }^{*} \mathrm{C}$ indicates statistical significance from $\mathrm{C}$ at $p<0.05 .{ }^{*} \mathrm{~N}_{1}$, ${ }^{*} \mathrm{CV}_{1}$ and ${ }^{*} \mathrm{IV}_{2}$ indicate statistical significance from $\mathrm{N}_{1}, \mathrm{CV}_{1}$ and $\mathrm{IV}_{2}$ respectively $(p<0.05)$.

Figure 5 indicates that $\mathrm{N}_{2}+\mathrm{CV}_{2}$ had rather additive combined effect.

Figure 6 concerns $\mathrm{N}_{8}$-noise added with each vibration. $\mathbf{N}_{3}+\mathrm{CV}_{1}$ and $\mathrm{N}_{3}+\mathrm{CV}_{2}$ showed lower means of error rates than $\mathrm{N}_{3}$ or each of $\mathrm{CV}_{1}$ and $\mathrm{CV}_{2}(p<$ 0.05 ). But $N_{8}+I V_{1}$ and $N_{3}+I V_{2}$ showed little differences in mean of error rates from $I V_{1}$ and $I V_{2}$ respectively. $\mathrm{N}_{3}+\mathrm{CV}_{1}$ showed a larger sd of error rates than $\mathrm{N}_{8}(p<0.05) . \quad \mathrm{N}_{8}+\mathrm{IV}_{2}$ also showed a smaller sd of error rates than $\mathrm{N}_{3}$ or $\operatorname{IV}_{2}(p<0.05)$. $\mathrm{N}_{3}+\mathrm{CV}_{1}$ and $\mathrm{N}_{8}+\mathrm{CV}_{2}$ indicated elimination of the effects of the noise alone or the vibration alone. $\mathrm{N}_{8}+\mathrm{CV}_{1}$ and $\mathrm{N}_{8}+\mathrm{CV}_{2}$ also showed rather promotion in performance.

\subsection{Subjective Ratings of Disturbance}

Table 5 shows intercorrelations among the variables, partial correlations of each variable and

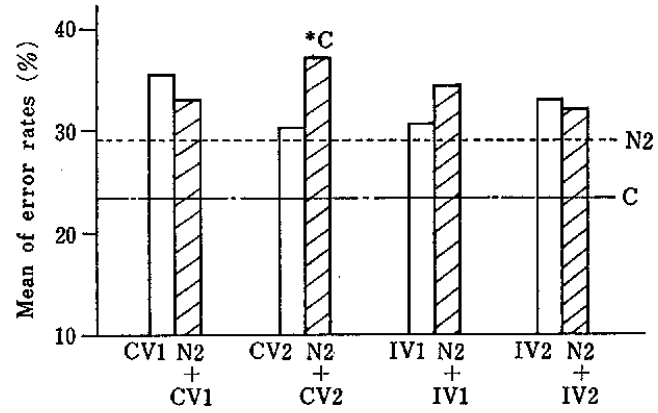

(a) Mean of error rates.

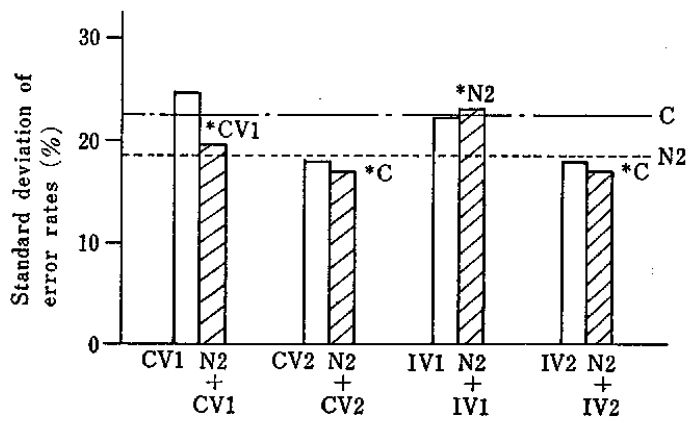

(b) Standard deviation of error rates.

Fig. 5 Estimated combined effects of noise and vibration under $\mathrm{N}_{2}+\mathrm{CV}_{1}, \mathrm{~N}_{2}+\mathrm{CV}_{2}$, $\mathrm{N}_{2}+\mathrm{IV}_{1}$ and $\mathrm{N}_{2}+\mathrm{IV}_{2} .{ }^{*} \mathrm{C},{ }^{*} \mathrm{CV}_{1}$ and ${ }^{*} \mathrm{~N}_{2}$ indicate statistical significance from $\mathbf{C}$, $\mathrm{CV}_{1}$ and $\mathrm{N}_{2}$ respectively $(p<0.05)$.

multiple correlation in the analysis for the subjective ratings of disturbance. Table 5 showed a high multiple correlation $(p<0.001)$. The variable of NV showed a highest partial correlation $(p<0.001)$. The Sub and the Mt also showed high partial correlations $(p<$ 0.001), but Ses showed rather low partial correlation $(p<0.05)$. Intercorrelations among the variables showed low correlations. These means that the subjective ratings of disturbance could be explained by these four variables.

Figure 7 shows relationships between subjective ratings of disturbance and means of error rates (\%) for each condition of noise and vibration. The vertical axis represents quantified values of the ratings of disturbance (outside variable) for each condition of noise and vibration analyzed by the quantification method (Type 1). The horizontal axis also represents the quantified values of means of error rates (outside variable) for each condition of noise and vibration analyzed by the quantification 


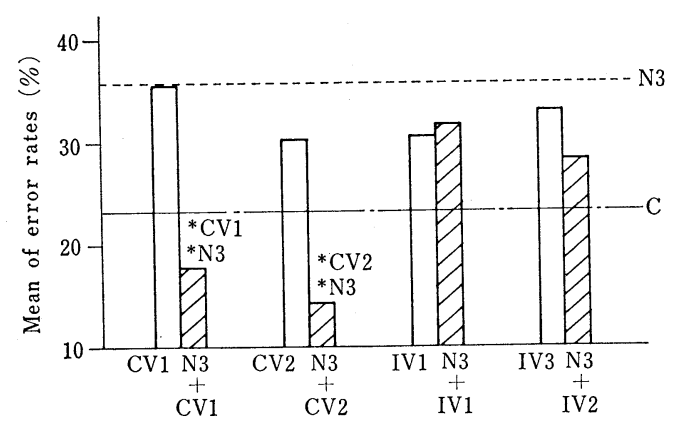

(a) Mean of error rates.

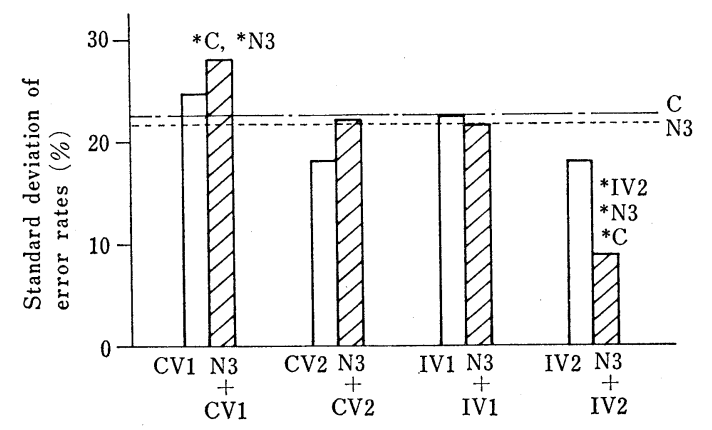

(b) Standard deviation of error rates.

Fig. 6 Estimated combined effects of noise and vibration under $\mathrm{N}_{3}+\mathrm{CV}_{1}, \mathrm{~N}_{3}+\mathrm{CV}_{2}$, $\mathrm{N}_{3}+\mathrm{IV}_{1}$ and $\mathrm{N}_{3}+\mathrm{IV}_{2}$. ${ }^{*} \mathrm{C},{ }^{*} \mathrm{~N}_{3}$ and $* \mathrm{IV}_{2}$ indicate statistical significance from $\mathrm{C}, \mathrm{N}_{3}$ and $\mathrm{IV}_{2}$ respectively $(p<0.05)$.

method (Type 1) (see Sect. 4.2).

Four groups of relationship between subjective ratings of disturbance and means of error rates were observed. $\mathrm{N}_{1}, \mathrm{~N}_{2}, \mathrm{~N}_{3}, \mathrm{~N}_{1}+\mathrm{CV}_{1}, \mathrm{~N}_{1}+\mathrm{CV}_{2}, \mathrm{~N}_{1}+$ $I V_{1}, N_{1}+I_{2}, N_{2}+C V_{1}, N_{2}+C V_{2}, N_{2}+I_{1}$ and $N_{2}+$ $\mathrm{IV}_{2}$ were estimated to fall under the group (a). $\mathrm{N}_{1}+$

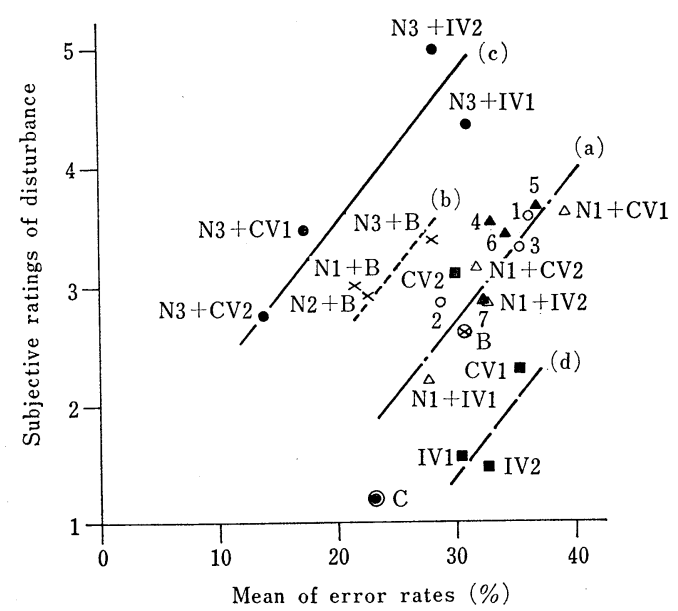

Fig. 7 Estimated subjective ratings of disturbance in relation to mean of error rates. Parentheses of (a), (b), (c) and (d) indicate the groups showed in Table 6. Numbers in this figure indicate the conditions in the following; 1: $\mathrm{N}_{1}, 2: \mathrm{N}_{2}, 3$ : $\mathrm{N}_{3}, 4: \mathrm{N}_{2}+\mathrm{CV}_{1}, 5: \mathrm{N}_{2}+\mathrm{CV}_{2}, 6: \mathrm{N}_{2}+\mathrm{IV}_{1}$, 7: $\mathrm{N}_{2}+\mathrm{IV}_{2}$.

B, $\mathrm{N}_{2}+\mathrm{B}$ and $\mathrm{N}_{3}+\mathrm{B}$ fell under the group (b). $\mathrm{N}_{3}+$ $\mathrm{CV}_{1}, \mathrm{~N}_{3}+\mathrm{CV}_{2}, \mathrm{~N}_{3}+\mathrm{IV}_{1}$ and $\mathrm{N}_{3}+\mathrm{IV}_{2}$ fell under the group (c). $\mathrm{CV}_{1}, \mathrm{IV}_{1}$ and $\mathrm{IV}_{2}$ fell under the group (d). Regression lines of each group were estimated as having same regression coefficients to each other and different constants from each other (see Tables 6 and 7). In these groupings of relationship between subjective ratings of disturbance and means of error rates, $\mathrm{CV}_{2}$ and $\mathrm{B}$ were estimated to fall under the group (a). These were different tendencies from preliminary consideration of grouping that would be estimated to fall under the group (d) or (b) respec-

Table 5 Intercorrelations among the variables, partial correlations of each variable and multiple correlation analyzed by Hayashi's Quantification Method (Type 1) as regards subjective ratings of disturbance in PAL by noise and vibration.

\begin{tabular}{lcccc}
\hline \multicolumn{1}{c}{ Variables } & Noise and vibration & Subjects & Sessions & Materials \\
\hline Subjects & -0.141 & & & \\
Sessions & -0.041 & -0.032 & 0.012 & \\
Materials & -0.107 & 0.013 & $0.202^{*}$ & $0.449^{* * *}$ \\
\hline (Partial correlation) & $0.753^{* * *}$ & $0.653^{* * *}$ & & \\
(Multiple correlation) & $0.815^{* * *}$ & & & \\
\hline
\end{tabular}

$* * *$ and $*$ show statistical significance at levels of $p<0.001$ and $p<0.05$ respectively. 
Table 6 Result of analysis of variance for regressions of subjective ratings of disturbance on means of error rates.

\begin{tabular}{lcrl}
\hline \multicolumn{1}{c}{ Source } & SS & f & MS \\
\hline $\begin{array}{l}\text { Differences among } \\
\text { constants }\end{array}$ & 14.609 & 3 & $4.870^{* * *}$ \\
$\begin{array}{l}\text { Residual (1) } \\
\begin{array}{l}\text { Differences among } \\
\text { regression coefficients }\end{array}\end{array}$ & 2.080 & 19 & 0.109 \\
Residual (2) & 1.845 & 16 & 0.115 \\
\hline
\end{tabular}

*** shows statistical significance $(p<0.001)$.

Table 7 Regression coefficient and constants of the estimated lines of subjective ratings on means of error rates.

\begin{tabular}{cccc}
\hline Groups & $\begin{array}{c}\text { Conditions of noise } \\
\text { and vibration }\end{array}$ & Constants & $\begin{array}{c}\text { Regression } \\
\text { coefficients }\end{array}$ \\
\hline (a) $\mathrm{N}_{1}, \mathrm{~N}_{2}, \mathrm{~N}_{3}, \mathrm{~N}_{1}$ comb., & -1.03 & \\
& $\mathrm{~N}_{2}$ comb. & & \\
(b) & $\mathrm{N}_{1}+\mathrm{B}, \mathrm{N}_{2}+\mathrm{B}, \mathrm{N}_{3}+\mathrm{B}$ & 0.06 & \\
(c) $\mathrm{N}_{3}+\mathrm{CV}_{1}, \mathrm{~N}_{3}+\mathrm{CV}_{2}$, & 1.08 & 0.124 \\
& $\mathrm{~N}_{8}+\mathrm{IV}_{1}, \mathrm{~N}_{3}+\mathrm{IV}_{2}$ & & \\
(d) $\mathrm{CV}_{1}, \mathrm{IV}_{1}, \mathrm{IV}_{2}$ & -2.31 & \\
\hline
\end{tabular}

These estimated regression lines are shown in Fig. 7. $\mathrm{N}_{1}$ comb. in this table indicate the conditions of $\mathrm{N}_{1}+\mathrm{CV}_{1}, \mathrm{~N}_{1}+\mathrm{CV}_{2}, \mathrm{~N}_{1}+\mathrm{IV}_{1}$ and $\mathrm{N}_{1}+\mathrm{IV}_{2} . \mathrm{N}_{2-}$ comb. in this table also indicate $\mathrm{N}_{2}+\mathrm{CV}_{1}, \mathrm{~N}_{2}+$ $\mathrm{CV}_{2}, \mathrm{~N}_{2}+\mathrm{IV}_{1}$ and $\mathrm{N}_{2}+\mathrm{IV}_{2}$. tively. C was estimated to fall under the group (a). As the results, it was shown that the group (c) was most disturbing in spite of indicating rather low means of error rates, especially $\mathrm{N}_{8}+\mathrm{IV}_{1}$ or $\mathrm{N}_{3}+\mathrm{IV}$, and that the group (d) was least disturbing in spite of indicating rather high means of error rates (Fig. 7, Table 7).

Figure 8 shows relationships between subjective

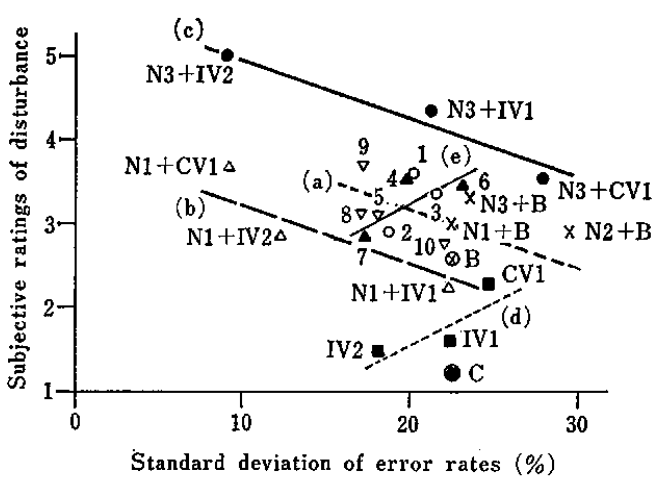

Fig. 8 Estimated subjective ratings of disturbance in relation to standard deviation of error rates. Parentheses of (a), (b), (c), (d) and (e) indicate the groups estimated in Table 8. Numbers in this figure indicate the conditions in the following; $1: \mathrm{N}_{1}, 2$ : $\mathrm{N}_{2}, 3: \mathrm{N}_{8}, 4: \mathrm{N}_{2}+\mathrm{CV}_{1}, 5: \mathrm{CV}_{2}, 6: \mathrm{N}_{2}+$ $I V_{1}, 7: \mathrm{N}_{2}+\mathrm{IV}_{2}, 8: \mathrm{N}_{1}+\mathrm{CV}_{2}, 9: \mathrm{N}_{2}+\mathrm{CV}_{2}$, 10: $\mathrm{N}_{3}+\mathrm{CV}_{2}$.

Table 8 Results of analyses of variance for regressions of subjective ratings of disturbance on standard deviations of error rates.

\begin{tabular}{|c|c|c|c|c|}
\hline Analytical group No. & Source & SS & f & MS \\
\hline \multirow{4}{*}{$\begin{array}{c}{[1]} \\
\text { (a), (b), (c) }\end{array}$} & $\begin{array}{l}\text { Differences } \\
\text { among constants }\end{array}$ & 4.787 & 2 & $2.394^{* * *}$ \\
\hline & Residual (1) & 0.946 & 10 & 0.095 \\
\hline & $\begin{array}{l}\text { Differences } \\
\text { among regression } \\
\text { coefficients }\end{array}$ & 0.218 & 2 & 0.109 \\
\hline & Residual (2) & 0.727 & 8 & 0.091 \\
\hline \multirow{4}{*}{$\begin{array}{c}{[2]} \\
\text { (d), (e) }\end{array}$} & $\begin{array}{l}\text { Differences } \\
\text { among constants }\end{array}$ & 4.974 & 1 & $4.974^{* * *}$ \\
\hline & Residual (1) & 0.425 & 6 & 0.071 \\
\hline & $\begin{array}{l}\text { Differences } \\
\text { among regression } \\
\text { coefficients }\end{array}$ & 0.00003 & 1 & 0.000 \\
\hline & Residual (2) & 0.425 & 5 & 0.085 \\
\hline
\end{tabular}

*** shows statistical significance $(p<0.001)$. 


\section{T. YOSHIDA and N. SAKATA: EFFECTS OF NOISE AND VIBRATION ON TASK}

Table 9 Regression coefficients and constants of the estimated lines of subjective ratings on means of error rates.

\begin{tabular}{cllrc}
\hline \multicolumn{2}{c}{ Groups } & \multicolumn{1}{c}{$\begin{array}{c}\text { Conditions of noise } \\
\text { and vibration }\end{array}$} & Constants & $\begin{array}{c}\text { Regression } \\
\text { coefficients }\end{array}$ \\
\hline \multirow{2}{*}[1]{} & (a) & $\mathrm{B}, \mathrm{Bcomb}, \mathrm{CV}_{2}, \mathrm{CV}_{2}$ comb. & 4.58 & \\
& (b) & $\mathrm{N}_{1}+\mathrm{CV}_{1}, \mathrm{~N}_{1}+\mathrm{IV}_{1}, \mathrm{~N}_{1}+\mathrm{IV}_{2}$ & 3.92 & -0.0706 \\
& (c) & $\mathrm{N}_{3}+\mathrm{CV}_{1}, \mathrm{~N}_{2}+\mathrm{IV}_{1}, \mathrm{~N}_{3}+\mathrm{IV}_{2}$ & 5.67 & \\
\hline & (d) & $\mathrm{CV}_{1}, \mathrm{IV}_{1}, \mathrm{IV}_{2}$ & -0.55 & 0.108 \\
& (e) & $\mathrm{N}_{1}, \mathrm{~N}_{2}, \mathrm{~N}_{3}, \mathrm{~N}_{2}+\mathrm{CV}_{1}$, & 1.11 & \\
& & $\mathrm{~N}_{2}+\mathrm{IV}_{1}, \mathrm{~N}_{2}+\mathrm{IV}_{2}$ & & \\
\hline
\end{tabular}

These estimated regression lines are shown in Fig. 8. Bcomb. in this table indicate the conditions of $\mathrm{N}_{1}+\mathrm{B}$, $\mathrm{N}_{2}+B$ and $\mathrm{N}_{3}+\mathrm{B}$. $\mathrm{CV}_{2}$ comb. in this table also indicate the conditions of $\mathrm{N}_{1}+\mathrm{CV}_{2}, \mathrm{~N}_{2}+\mathrm{CV}_{2}$ and $\mathrm{N}_{3}+\mathrm{CV}_{2}$.

ratings of disturbance and standard deviations of error rates $(\%)$ for each condition of noise and vibration. The vertical axis represents the quantified values of the subjective ratings of disturbance (outside variable) for each condition of noise and vibration (same to those in Fig. 7). The horizontal axis also represents the quantified values of standard deviations of error rates (outside variable) for each condition of noise and vibration analyzed by the quantification method (Type 1) (see Sect. 4.2). It was also observed in Fig. 8 that five groups of relationship between subjective ratings of disturbance and sd's of error rates. The groups of (a), (b) and (c) were estimated as having same regression coefficients to each other, and the groups of (d) and (e) were also estimated as having same regression coefficients (see Table 8) that were different from the coefficient of the group of (a), (b) and (c) (see Table 9). B, $\mathrm{N}_{1}+\mathrm{B}, \mathrm{N}_{2}+\mathrm{B}, \mathrm{N}_{3}+\mathrm{B}, \mathrm{CV}_{2}, \mathrm{~N}_{1}+\mathrm{CV}_{2}, \mathrm{~N}_{2}+$ $\mathrm{CV}_{2}$ and $\mathrm{N}_{8}+\mathrm{CV}_{2}$ fell under the group (a). $\mathrm{N}_{1}+\mathrm{CV}_{1}$, $N_{1}+I V_{1}$ and $N_{1}+I V_{2}$ fell under the group (b). $N_{8}+$ $C V_{1}, N_{3}+I V_{1}$ and $N_{3}+I V_{2}$ fell under the group (c). $C V_{1}, I V_{1}$ and $I V_{2}$ fell under the group (d). $N_{1}, N_{2}$, $N_{3}, N_{2}+C V_{1}, N_{2}+I V_{1}$ and $N_{2}+I V_{2}$ fell under the group (e). The conditions in the group of (a), (b) or (c) indicated that subjective ratings of disturbance increased in proportion to decreasing sd's of error rates, while the conditions in the group of (d) or (e) indicated that subjective ratings of disturbance increasing in proportion to increasing sd's of error rates (Fig. 8). C was estimated to be not belonged to the groups mentioned above in Fig. 8.

\section{DISCUSSION}

The results to date in the effects of noise and vibration are inconclusive, because of difficulties in the experimental control of the variables affecting on the task performance. Therefore, it is difficult to summarize simply the effects of noise and vibration. ${ }^{14,15)}$ Nevertheless, some suggestive results were obtained in this study.

The main variables affecting on the task in this study were NV (noise and vibration), Sub (subjects), Mt (materials for memory) and Ses (sessions) (Tables 3 and 4). The results in the analyses by Hayashi's Quantification Method (Type 1) showed that these variables did not correlate to each other in mean and standard deviation (sd) of error rates, except Ses in sd of error rates (Tables 3 and 4). Ses in sd of error rates showed correlation to $\mathrm{NV}$ and $\mathrm{Mt}$, but showed a rather low partial correlation. Therefore, the estimated mean and standard deviation of error rates in each condition of noise and vibration can be considered to be fairly clear effects of noise and vibration, although the levels of noise or vibration were rather low or moderate. The results in Table 5 also showed that the estimated subjective ratings of disturbance were clear effects of noise and vibration. Many earlier researchers employed such experiments as the subjects were tested on the set task under the conditions of noise and quiet. ${ }^{4-8}$ ) In such experiments, equal capabilities for performance between two groups of subjects can be not always matched, though they are randomly selected in a larger group. ${ }^{14)}$ So each subject was examined under $2 / 3$ of all conditions of noise and vibration under the block design in this study. Then Tables $3 \sim 5$ indicated reasonable results as mentioned above.

$N_{1}$ and $N_{2}$ produced clearly detrimental effects in mean of error rates as compared with the control. 
$N_{2}$ also indicated the same tendency to $N_{1}$ and $N_{3}$. Yoshida demonstrated that the noise at equivalent levels to those in this study produced the promotive effects on the same task. ${ }^{9}$ ) Although the durations for memorization and recall was longer in the previous study ${ }^{9)}$ than in this study, the mean error rates of all data were equivalent. The durations were employed, because the subjects in this study indicated higher performance and less error in preliminary training tests. Reason for this discrepancy (detrimental or promotive) would be that distraction and arousal were different between intermittent and continuous noise. The intermittent noise in this study was randomly varying in intervals and durations and was unfamilier to the subjects. So the intermittent noise produced the detrimental effects on the task. ${ }^{16}$ ) It is suggested that distraction would not appear in the same scalar dimension to arousal, and that arousal would be multidimensional. ${ }^{8,9)}$

$\mathrm{CV}_{1}$ indicated clearly detrimental effects, but $\mathrm{CV}_{2}$, $I V_{1}$ and $I V_{2}$ indicated no effects or little deterioration in performance (Fig. 3). These effects would be mainly due to $B$, because the effects of the vibration alone indicated the effects near to B (Fig. 3). Reason for this may be that the intensity of the vibration was too low. ${ }^{17)}$ Nevertheless, the vibration when it was added with noise indicated the different effects from the effects of the conditions with B (Figs. 4 6). Especially, $\mathrm{N}_{3}+\mathrm{CV}_{1}$ and $\mathrm{N}_{3}+\mathrm{CV}_{2}$ indicated rather promotive effects on performance. It seems that $\mathrm{N}_{3}$ (higher intensity) masked the effects of $\mathrm{B}$ and the vibration $\left(\mathrm{CV}_{1}, \mathrm{CV}_{2}\right)$. The other combined conditions indicated similar effects of the vibration alone, although $\mathrm{N}_{2}+\mathrm{CV}_{2}$ indicated rather additive effects (Figs. 3 6). It seems that the effects of dominant stressor appeared in the combined conditions as well as in the vibration alone. $\mathrm{N}_{2}+\mathrm{CV}_{2}$ showed rather additive effects (Fig. 5). Such effects were also shown in the previous paper. ${ }^{\circ)}$ Therefore, it is inconclusive about the combined effects. ${ }^{18)}$ But additive effects of the combined conditions would appear in balancing the effects of each stressor. It is suggested combined stressors may probably change arousal from the arousal of each stressor (noise and vibration) in balancing or filtering each arousal of noise and vibration in accordance with demand of the task.

As regards subjective ratings of disturbance, interest results were observed (Figs. 7 and 8). The disturbance indicated the clear proportion to mean or standard deviation of error rates in each of some groups respectively. $\mathrm{CV}_{1}, \mathrm{IV}_{\mathbf{1}}$ and $I \mathrm{~V}_{\mathbf{2}}$ showed high error rates in mean in spite of low disturbance. $\mathrm{N}_{3}$ added with the vibration showed rather low error rates in mean against showed high disturbance, especially $\mathrm{N}_{8}+I V_{1}$ and $\mathrm{N}_{8}+I V_{2}$. These indicates that high error rates does not always accompany high disturbance. So it should be taken account for such relationships between error rates and disturbance when some conditions of noise and vibration will be compared in performance. By the way, Fig. 8 showed two tendency in relationship between the standard deviation and the disturbance. The noise or vibration alone, except the conditions with $B$, showed increasing standard deviation of error rates as increasing disturbance. But the combined conditions as well as the conditions with B showed decreasing standard deviation of error rates as increasing disturbance. So it is suggested that some concentration in performance may produced higher disturbance and that it may show high error rates in mean and small standard deviations of error rates.

In summary, it was observed that $N_{1}$ and $N_{3}$ produced detrimental effects and that $\mathbf{N}_{2}$ indicated the same tendency to $\mathrm{N}_{1}$ or $\mathrm{N}_{3}$. It was also observed that $\mathrm{N}_{3}+\mathrm{CV}_{1}$ and $\mathrm{N}_{8}+\mathrm{CV}_{2}$ indicated elimination of each effect of the noise and the vibration alone. Further, it was demonstrated that high disturbance did not always accompany high error rates in mean or standard deviation of the paired associates learning task.

\section{ACKNOWLEDGEMENTS}

The authors would like to acknowledge the helpful advices for Dr. Y. Osada and Dr. H. Yamazaki. The authors also thank to support this study for the members of Railway Labour Science Research Institute.

\section{REFERENCES}

1) A. T. Purcell and R. H. Thorne, "An alternative method for assessing the psychological effects of noise in the field," J. Sound Vib. 55, 533-544 (1977).

2) J. W. Sargent and W. A. Utley, "The disturbance caused to school teachers by noise," J. Sound Vib. 70, 557-572 (1980).

3) J. Lambert, F. Simonnet, and M. Vallet, "Patterns of behaviour in dwellings exposed to road traffic noise," J. Sound Vib. 92, 159-172 (1984).

4) N. D. Weinstein, "Effect of noise on intellectual performance," J. Appl. Psychol. 59, 548-554 (1974).

5) W. E. Teichner, E. Arees, and R. Reilly, "Noise and human performance: A psychological approach," 


\section{T. YOSHIDA and N. SAKATA: EFFECTS OF NOISE AND VIBRATION ON TASK}

Ergonomics 6, 83-97 (1963).

6) C. R. Johansson, "Effects of low intensity, continuous and intermittent noise on mental performance and writing pressure of children with different intelligence and personality characteristics," Ergonomics 26, 275-288 (1983).

7) J. L. Wheale and N. M. O'Shea, "Noise and the performance of a four-choice psychomotor task," Ergonomics 25, 1053-1064 (1980).

8) M. Loeb, "Noise and performance: Do we know more now?" ASHA-Reports 10, 303-321 (1980).

9) T. Yoshida, "Effects of noise and vibration on choice reaction time task and paired associates learning task," J. Acoust. Soc. Jpn. (E) 7, 315-323 (1986).

10) K. Yamazaki, "Effects of whole body vibration on human performance and physiological functions (Report 1),' Bull. Railw. Labour Sci. Res. Inst. 29, 41-51 (1975) (in Japanese).

11) S. Yasuda, Social Statistics (Maruzen, Tokyo, 1967), p. 189 (in Japanese).

12) S. Yasuda, Social Statistics (Maruzen, Tokyo, 1967), p. 194 (in Japanese).

13) T. Takagi, Studies on Quantification in Psychology (Tokyo-Daigaku-Shuppankai, Tokyo, 1969), p. 199 (in Japanese).

14) K. D. Kryter, The Effects of Noise on Man (Academic Press, New York, 1970), p. 550.

15) G. R. J. Hockey, "Effects of noise on human work efficiency," Handbook of Noise Assessment, ed. by D. N. May (Van Nostrand Reinhold Comp., New York, 1978), Chap. 14, p. 335.

16) A. J. Eschenbrenner, Jr., "Effects of intermittent noise on the performance of a complex psychomotor task," Hum. Factors 13, 59-63 (1971).

17) B. K. N. Rao and C. Ashley, "Effect of whole body low frequency random vertical vibration on a vigilance task," J. Sound Vib. 33, 119-125 (1974).

18) C. S. Harris and R. W. Shoenberger, "Combined effects of broad-band noise and complex waveform vibration on cognitive performance," Aviat. Space Environ. Med. 51, 1-5 (1980). 